\title{
ARTIGO CIENTÍFICO \\ Enriquecimento proteico do resíduo de abacaxi mediante fermentação semissólida
}

\section{Protein enrichment of pineapple residue by semisolid fermentation}

\author{
Gabriela Muricy de Souza Silva ${ }^{*}$, Jessyka Silva da Costa ${ }^{2}$, Maria do Carmo de Souza Cabral Filha ${ }^{3}$, Amanda Beatriz Sales \\ de Lima ${ }^{4}$, Osvaldo Soares da Silva ${ }^{5}$
}

\begin{abstract}
Resumo: A fermentação em estado semissólido executa um papel importante no aproveitamento de resíduos sólidos, devido à síntese de diferentes compostos, cujo grande interesse seja voltado para segmentos industriais. Objetivou-se estudar o processo de fermentação semissólida do resíduo de abacaxi, utilizando a levedura Saccharomyces cerevisiae, com 10\% de inoculo e avaliando o efeito da concentração inicial da levedura, assim como o tempo de fermentação sobre o teor proteico. O processo foi acondicionado em estufa de circulação de ar forçada a $55{ }^{\circ} \mathrm{C}$, durante 48 horas, sendo feita pesagens nos intervalos de 0 , 14 , 18, 24, 38, 42 e $48 \mathrm{~h}$ e realizadas analises físico-químicas e granulométrica. Mediante os resultados, observou-se uma diminuição da umidade com o passar do tempo chegando a atingir $0,91 \%$ ao final do estudo, já o teor proteico, aumentou consideravelmente, com proteína bruta de $14 \%$ para $20,56 \%$, após 48 h, o teor de sólidos solúveis totais apresentou um declínio possivelmente devido o consumo de carboidratos pela levedura. Foi realizada a análise granulométrica do resíduo, onde se observou que cerca de $80 \%$ das partículas apresentaram diâmetro maior que 2,4 milímetros. Através da fermentação semissólida dos resíduos de abacaxi foi possível elevar o teor proteico e aumentar a concentração de nutrientes, transformando um rejeito em um possível produto para destino humano ou animal com alto valor agregado.
\end{abstract}

Palavras-chave: Levedura; Proteína bruta; Análise granulométrica; Valor agregado.

Abstract: The fermentation in state semissólido executes an important paper in the use of solid residues, due to the synthesis of different compounds, which great interest is turned for industrial segments. The objective of this work studied the process of fermentation semissólida of the pineapple residues, using the yeast Saccharomyces cerevisiae, with $10 \%$ of inoculo and value the effect of the initial concentration of the yeast, as well as the time of fermentation on the proteinic tenor. The process was conditioned in stove of circulation of air forced to $55{ }^{\circ} \mathrm{C}$, during 48 hours, being done weighing in the intervals of $0,14,18,24$, 38, 42 and $48 \mathrm{~h}$ and carried out analyses chemical-physical and granulométrica. By means of the results, a reduction of the moisture was observed with the spending time coming reaching $0,91 \%$ to the end of the study, already the proteinic tenor, it increased considerably, with brutish protein of $14 \%$ for $20,56 \%$, after $48 \mathrm{~h}$, the tenor of total soluble solids presented a decline possibly owed the consumption of carbohydrates by the yeast. The analysis was carried out granulométrica of the residue, where it was noticed that nearly $80 \%$ of the particles presented diameter bigger than 2,4 millimeters. Through the fermentation semissólida of the pineapple residues it was possible to lift up the proteinic tenor and to increase the concentration of nutritious ones, transforming one I reject in a possible product for human or animal destiny with high collected value.

Key words: Leaven; Crude protein; Granulometric analysis; Value added.

\footnotetext{
*Autor para correspondência

Recebido para publicação em 10/10/2016; aprovado em 15/11/2016

${ }^{1}$ Engenheira de Alimentos, Universidade Federal de Campina Grande, Pombal-PB; (83)99644-0396, gabrielamuricy26@ hotmail.com.

${ }^{2}$ Engenheira de Alimentos, Universidade Federal de Campina Grande, jessykacosta07@yahoo.com.br

${ }^{3}$ Engenheira de Alimentos, Universidade Federal de Campina Grande, docarmocabral2@ hotmail.com

${ }^{4}$ Engenheira de Alimentos, Universidade Federal de Campina Grande, amanda_crows@ hotmail.com

${ }^{5}$ Prof. Doutor em Engenharia Química, Universidade Federal de Campina Grande, osvaldo_so2002@yahoo.com.br
} 


\section{INTRODUÇÃO}

O Brasil é um dos maiores produtores de abacaxi no mundo, com uma produção média de 2,5 toneladas nos anos de 2014 a 2015. Destacando-se o Pará (372.686 mil), Paraíba (290.772 mil) e Minas Gerais (263.133 mil) como os principais estados produtores na safra de 2015 (OCDE; FAO, 2015; IBGE, 2015).

O abacaxi (Ananás comosus (L.) Merril) é uma fruta muito apreciada em muitos países, por obter características específicas e propriedades nutritivas. É uma planta oriunda da América tropical e subtropical, possivelmente do Brasil, sendo amplamente cultivada nos trópicos (PIEDADE; CANNIATTI-BRAZACA, 2003).

Grande quantidade de resíduos é produzida em indústrias de alimentos, em especial na área de processamento de frutos como cascas, bagaço e caroços, ao longo de sua cadeia produtiva, o que gera perda de divisas, além de inúmeros problemas ambientais e desperdício (SENA; NUNES, 2006; ABUD; NARAIN, 2009). Esses resíduos possuem em sua composição: vitaminas, minerais, fibras e compostos antioxidantes, importantes para as funções fisiológicas (MATIAS et al., 2005).

A constante preocupação para reduzir os impactos ambientais gerados por resíduos no meio ambiente, possibilita a viabilização de propostas que levam o plano de produção industrial a ser elaborado de forma sustentável. Alguns resíduos gerados na indústria, podem ser reutilizados na unidade de processamento de alimentos, com finalidade de agregar valor aos produtos obtidos com aplicação de tecnologias adequadas, como demonstrados em alguns estudos (LAUFENBERG et al., 2003; KOBORI; JORGE, 2005; PELIZER et al., 2007; ALEXANDRE, 2013).

Resíduos provenientes do abacaxi podem ser empregados na elaboração de suplementos através do enriquecimento proteico por crescimento celular. São utilizados microrganismos, como, Saccharomyces cerevisiae, para que aconteça processo fermentativo, com finalidade de aumentar seu teor proteico e posteriormente ser utilizado como alimento humano e animal, não evidenciando características patogênicas, além de obter funções iguais de qualquer ser vivo que, respira, alimenta-se e excreta (RODRIGUES, 2001; ROCHA, 2002; PINTO et al., 2005).

A capacidade da transformação proteica por microrganismos depende de elementos como: ar, temperatura, oxigênio e disponibilidade de nutrientes. Campos (2005), Oliveira (2007), Araújo (2008) e Araújo (2009), verificaram o enriquecimento proteico em resíduos de frutos, alimentos ou planta, com a levedura Saccharomyces cerevisiae, através da fermentação semissólida. Esse método ocorre um crescimento de microrganismos sobre ou dentro de partículas em matriz sólida, mantendo-se a atividade de água do meio favorável para o procedimento (ALCÂNTARA et al., 2007).

Apesar disso, além do enriquecimento proteico é necessário ter a visão de que o produto deve ser conservado, livre de fatores que contribuam sua deterioração. Assim, mantê-los em estufa até umidade constante, está incluído a técnica de secagem. Refere-se a um processo bastante utilizado para preservação da qualidade de alimentos, devido à redução de grande quantidade de água, criando condições desfavoráveis para o crescimento de microrganismo em um determinado estágio, assim, promovendo ao produto longos períodos de armazenamento ao mesmo tempo conservando as suas características físicas e nutritivas (MARTINAZZO, 2010; EMBRAPA, 2015).

Objetivou-se estudar o processo de fermentação semissólida do resíduo de abacaxi, utilizando a levedura Saccharomyces cerevisiae, com $10 \%$ de inoculo avaliando o efeito da concentração inicial da levedura assim como o tempo de fermentação sobre o teor proteico.

\section{MATERIAL E MÉTODOS}

O trabalho foi executado no Laboratório de Produção de Sementes em conjunto com os Laboratórios de Tecnologia de Grãos e Cereais, Fenômenos de Transporte e Operações Unitárias, todos pertencentes à Unidade Acadêmica de Tecnologia de Alimentos (UATA), no Centro de Ciências e Tecnologia Agroalimentar (CCTA), da Universidade Federal de Campina Grande, Campus Pombal - PB.

A matéria-prima utilizada foi o resíduo de abacaxi contendo a casca e coroa, adquirido junto a Universidade Federal de Campina Grande (UFCG), Pombal-PB, após descarte do mesmo. Para o enriquecimento proteico do substrato, utilizou-se a levedura Saccharomyces cerevisiae, fermento biológico para processamento de pães e seus derivados, obtida no comercio local da cidade de Pombal-PB.

A fermentação semissólida foi realizada visando o estudo feito por Oliveira (2007), mas com adaptações. Em um biorreator retangular, colocou-se $1000 \mathrm{~g}$ de substrato triturado em pequenas partículas e adicionou $10 \%$ da levedura, logo, o processo foi acondicionado em uma estufa com circulação de ar forçada a $55^{\circ} \mathrm{C}$ de temperatura, durante $48 \mathrm{~h}$. Foram feitas pesagens dessas amostras nos intervalos de 0, 14, 18, 24, 38, 42 e $48 \mathrm{~h}$, todas em triplicata.

Sendo assim, para a caracterização do resíduo enriquecido, procedeu-se com a trituração do material em um moinho elétrico e colocou-se em recipientes de plásticos herméticos, armazenados em temperatura ambiente para a determinação das analises de umidade, proteína e sólidos solúveis totais, em cada tempo analisado.

A análise de umidade, proteínas e sólidos solúveis totais foram realizadas seguindo a metodologia do Instituto Adolfo Lutz (2008). Para determinação de umidade, a amostra do resíduo enriquecido foi colocada em uma estufa a uma temperatura de $105{ }^{\circ} \mathrm{C}$, até peso constante. O teor de proteínas foi determinado pelo método de Kjeldahl modificado, no qual se baseia em três etapas: digestão, destilação e titulação. A determinação do parâmetro de sólidos solúveis totais ( ${ }^{\circ}$ Brix) foi feita utilizando refratômetro digital. Todas as análises foram realizadas em triplicata.

Para a granulometria do material seco foram utilizadas peneiras com aberturas de 4,$0 ; 2,8 ; 2,0 ; 1,4$ e $0,5 \mathrm{~mm}$, equivalentes a 5,$15 ; 3,4 ; 2,4 ; 1,7 ; 0,95 \mathrm{~mm}$ (Diâmetro médio das peneiras), respectivamente, e um agitador magnético para realizar o peneiramento, de acordo com a metodologia do Instituto Adolfo Lutz (2008). Primeiramente, pesaram-se as peneiras para posteriormente serem ajustadas de maneira vertical no agitador, logo, colocou-se $39,5 \mathrm{~g}$ do material na peneira de maior diâmetro e após 15 minutos de agitação constante foi realizada medição da massa em cada uma das bandejas utilizadas.

Na Figura 1 tem-se a ilustração de diferentes etapas do resíduo de abacaxi que foi utilizado como substrato para o enriquecimento proteico. 
Figura 1. Resíduo de abacaxi enriquecido através do cultivo semissólido: Triturado (A), Com adição da levedura (B), após secagem (C) e Torre Granulométrica (D).

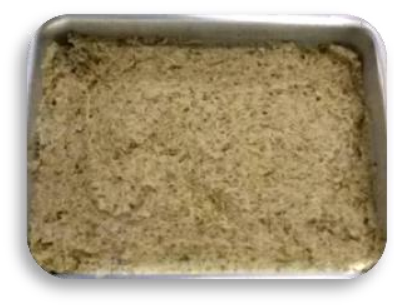

A.

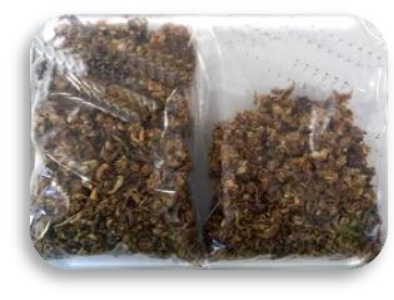

C.

Fonte: Autoria própria

\section{RESULTADOS E DISCUSSÃO}

A Figura 2 demonstra os resultados obtidos para a caracterização do resíduo de abacaxi enriquecido. Observa-se uma perda gradativa da umidade com o passar do tempo (Figura 2A), até o final da fermentação, fenômeno que pode ser justificado quando submete a levedura a uma temperatura constante, o que implica um comportamento favorável ao processo fermentativo, sendo essa diminuição da umidade de extrema importância para que ocorra uma concentração de nutrientes no produto. Alexandre et al. (2013) observaram comportamento semelhante ao avaliar as características cinéticas envolvidas no processo de secagem do resíduo de abacaxi enriquecido.

Através do gráfico de umidade verifica-se o teor de umidade inicial de $73,25 \%$ até $0,91 \%$ em seu valor final no resíduo enriquecido. Oliveira et al. (2009) estudando o equilíbrio higroscópico da casca de abacaxi afirmaram que para enriquecer proteicamente o resíduo, deve-se iniciar o processo com umidade acima de $80 \%$, valor inferior foi demostrado nesse estudo, Sousa (2009) em sua pesquisa de cultivo semissólido do resíduo de abacaxi e goiaba afirma que o teor inicial de umidade do substrato pode variar entre 30 e $85 \%$, valor equivalente observou-se no devido trabalho.

É possível visualizar na Figura 2 a caracterização físicoquímica do resíduo enriquecido.

O teor de proteína encontrado no resíduo de abacaxi (Figura 2B) foi de 5, 25\% no início do processo, apresentando uma estabilização entre 24 e 38 horas em $14 \%$ de proteína, voltando posteriormente a aumentar, e ao término da fermentação atingiu 20,56\% em 48 horas de fermentação.
Figura 2. Caracterização físico-química do resíduo do abacaxi enriquecido em função do tempo de secagem: Teor de umidade (A), proteína brutos (B) e sólidos solúveis totais (C).

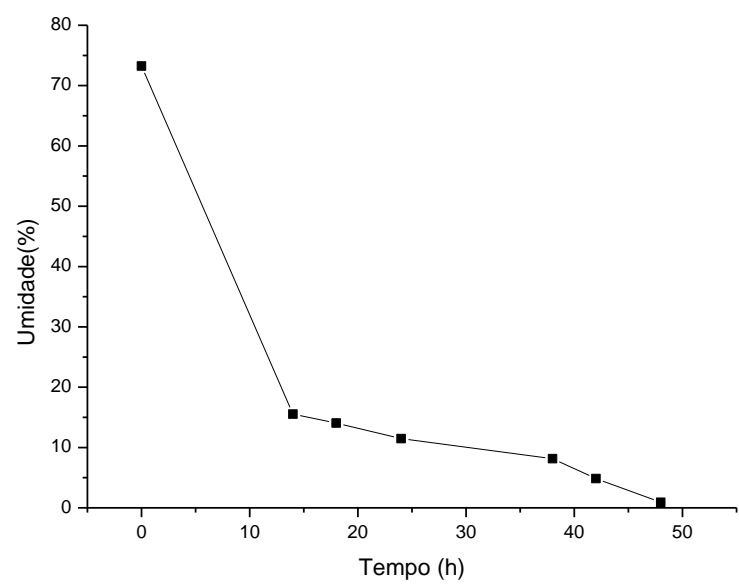

A.

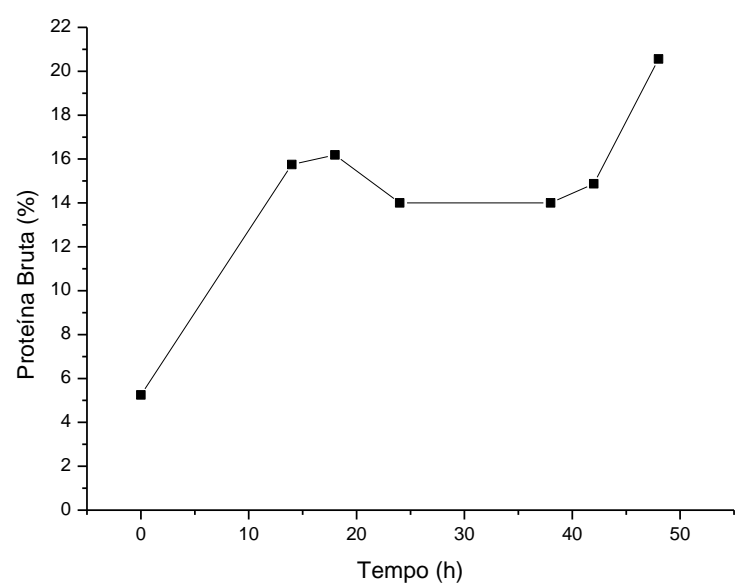

B.

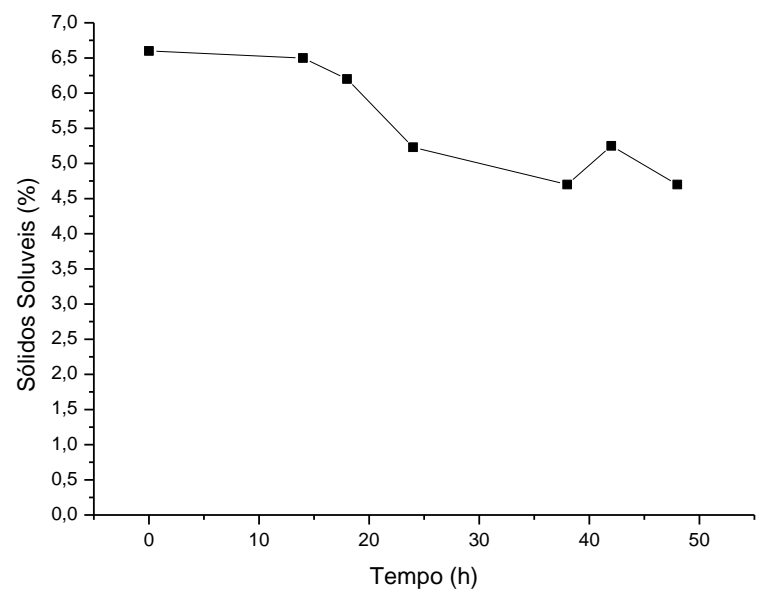

C.

Fonte: Autoria própria

Alexandre et al. (2013) observaram um teor inicial de proteína bruta in natura de $7,61 \%$ em resíduo da casca do abacaxi enriquecido com $3 \%$ da levedura Saccharomyces 
cerevisiae, valor maior que o encontrado no início do estudo e proteína bruta final semelhante com 20,21\%, após 48 h de fermentação.

Luciano et al. (2014), ao estudarem o enriquecimento proteico de resíduos do abacaxi contendo casca raspada, bagaço da polpa e do talo para alimentação alternativa de ruminantes com a mesma levedura e $2 \%$ de inoculo, observaram um teor inicial de proteína de $7,23 \%$, e após $48 \mathrm{~h}$ encontraram valores de $16,01 \%$ de proteína bruta, valor final inferior ao encontrado no presente estudo com o mesmo tempo de fermentação, o que pode ser justificado pela quantidade superior de inoculo utilizado nesta pesquisa que foi de $10 \%$.

Oliveira et al. (2006), estudaram o processo de enriquecimento nutricional dos resíduos do abacaxi, casca e coroa com a utilização da levedura Saccharomy cescerevisiae, através de fermentação semissólida até o tempo de 96 horas, verificaram que o tempo que maximizou o aumento proteico foi o de 48 horas com valor de $17,65 \%$.

Comparando os resultados obtidos com o enriquecimento proteico, Figura 2B, em relação ao resíduo in natura é possível notar a viabilidade deste bioprocesso, com um aumento considerável no teor de proteína bruta que chegou a quase quatro vezes o valor inicial da proteína determinada.

A taxa de consumo de açúcares durante a fermentação semissólida foi acompanhada através da variação no teor de sólidos solúveis totais ( ${ }^{\circ}$ Brix) (Figura $2 \mathrm{C}$ ), onde percebeu-se um declínio em relação ao valor inicial, em seguida um aumento, e novamente um declínio foi observado, provavelmente devido à presença da levedura no meio, que levou ao consumo de carboidratos durante a fermentação.

O teor de Sólidos Solúveis Totais pode-se observar valores variando de 6,6\% até 4,7\%. Lemos et al. (2010), ao estudarem a composição físico-química de resíduos de abacaxi in natura e desidratado, obtiveram, para tal parâmetro em abacaxi da variedade Jupi, 9,00\% e 26,66\%, respectivamente, e para amostras de abacaxi da variedade Pérola encontraram valores de $9,66 \%$ (in natura) e $21,66 \%$ (desidratado). Oliveira (2014), estudando os sólidos solúveis da casca e da coroa do abacaxi in natura encontrou 10,5 e 5,0 ${ }^{\circ}$ Brix, na devida ordem, demostrando diferença do parâmetro em resíduos de partes diferentes do mesmo fruto.

A diferença dos valores encontrados no trabalho com os citados na literatura pode ser justificada devido ao resíduo apresentar diferentes partes do fruto e pelo consumo dos carboidratos durante a fermentação. Segundo Uchoa et al. (2008), teores de sólidos solúveis são esperados altos para alimentos desidratados obtidos de resíduos, porém esses valores podem variar com o processamento aplicado na extração da polpa, fatores climáticos, variedade do fruto, tipos de solo e diversos outros fatores agronômicos.

Pode-se observar uma relação entre os parâmetros de proteínas e sólidos solúveis totais (Figura 2B e 2C), à medida que a levedura consome os carboidratos o teor de sólidos solúveis diminui e a proteína bruta aumenta durante a fermentação semissólida.

Correia et al. (2007), observando o alto teor de açúcares presente no resíduo do abacaxi, investigaram o enriquecimento proteico do resíduo por leveduras, indicando que açúcares presentes no meio atuam como eficientes fontes de carboidratos para o crescimento microbiano.
A Figura 3 mostra o histograma referente à análise granulométrica realizada em peneiras de diâmetros diferenciados, para as amostras de resíduo de abacaxi seco.

Figura 3. Distribuição granulométrica do resíduo de abacaxi seco: Fração Mássica em função do Diâmetro (A), Fração peneirada em função do Diâmetro (B), Fração retida em função do Diâmetro.
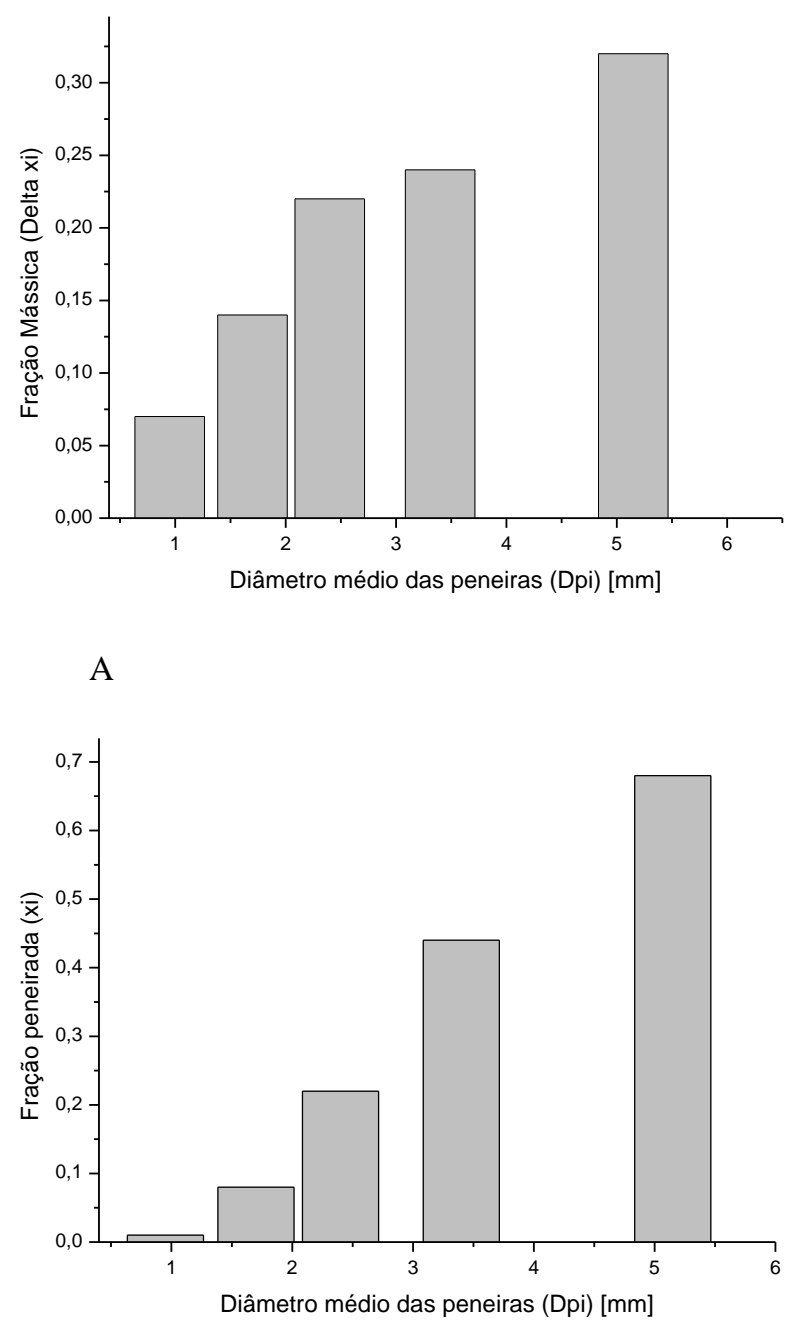

B

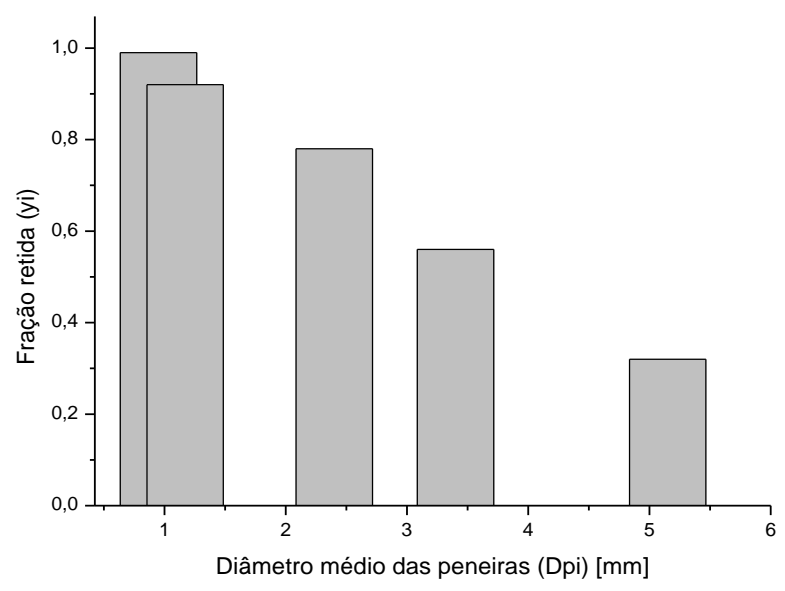

C

Fonte: Autoria própria 
Observa-se na Figura $3 \mathrm{~A}$ que em torno de $80 \%$ das partículas, apresentaram um diâmetro maior que $2,4 \mathrm{~mm}$. A peneira de tamanho $5,15 \mathrm{~mm}$, ficou com a maior parte do resíduo com 32,0\%, percebe-se que seria necessário acrescentar uma peneira de diâmetro maior, para obedecer à distribuição normal, tornando-se relativamente uniforme, pois a distribuição do material seco poderia passar para próxima peneira.

A Figura 3 (B e C) demonstra os valores de xi (Fração Peneirada) e yi (Fração Retida) dispostas em função do Dpi (Diâmetro Médio das peneiras), verificando que os valores xi $(0,01$ até 0,68$)$ aumentam a medida que a o diâmetro fica maior, sendo o inverso referente a yi $(0,99$ até 0,32$)$.

O tamanho das partículas do resíduo seco adquirido com o meio fermentativo e a secagem, devem apresentar uma forma que não seja muito grande e nem pequenos. Pois partículas maiores quando distribuídas no procedimento da fermentação semissólida, por obter maiores espaços interpartículas, podem vir a prejudicar os microrganismos na absorção de nutrientes. Já partículas pequenas, apesar de oferecerem uma maior área superficial e grau de transformação ao ataque microbiano, dificultam a respiração e aeração do sistema, provocando dissipação de gases e calor produzido, além de prejudicar no rendimento do processo (ALCÂNTARA et al., 2007; ALCÂNTARA et al., 2013; SOUZA et. al., 2010).

Assim, diante destas restrições e características importantes para eficácia desse bioprocesso, o estudo sob a determinação granulométrica do resíduo foi de grande relevância para identificar as frações em função dos diâmetros, e assim, ser referência para outros trabalhos futuros. De acordo com Alcântara et al., (2007) outro ponto que pode ser evidenciado sobre a caracterização realizada para as culturas, é o fato de variações e mudanças conforme a época de colheita, dos fenômenos e práticas agrícolas referentes ao plantio.

\section{CONCLUSÕES}

O resíduo de abacaxi, após a fermentação semissólida, possuiu grande potencial nutritivo, sendo capaz de satisfazer uma determinada população que almejam produtos alimentícios com alto teor proteico, principalmente.

Com a caracterização granulométrica verifica-se o tamanho das partículas dos resíduos, mostrando de extrema importância na finalidade, por exemplo, de usos como matérias primas em variados produtos.

Com esse tipo de bioprocesso possibilita a transformação de resíduo em um possível produto com alto valor agregado.

\section{REFERÊNCIAS}

ABUD, A. K. S; NARAIN, N. Incorporação da farinha de resíduo do processamento de polpa de fruta em biscoitos: uma alternativa de combate ao desperdício. Brazilian Journal Food Technology, v. 12, n. 4, p. 257-265, 2009.

ALCÂNTARA, S. R.; ALMEIDA, F. A. C.; SILVA, F. L. H. Emprego do Bagaço Seco do pedúnculo do caju para posterior utilização em um processo de fermentação semissólida. Revista Brasileira de Produtos Agroindustriais, Campina Grande, v.9, n.2, p.137-142, 2007.

ALCÂNTARA, S.R.; SOUSA, C.A.B.; ALMEIDA, F.A.C.; GOMES, J. P. Caracterização físico-química das farinhas do pedúnculo do caju e da casca do maracujá. Revista Brasileira de Produtos Agroindustriais, Campina Grande, v.15, n.4, p.349-355, 2013.

ALEXANDRE, H. V.; SILVA, F. L. H.; GOMES, J. P.; SILVA, O. S.; CARVALHO, J. P. D.; LIMA, E. E. Cinética de secagem do resíduo de abacaxi enriquecido. Revista Brasileira de Engenharia Agrícola e Ambiental, Campina Grande, v.17, n.6, p.640-646, 2013.

ARAÚJO L. F.; DIAS M. V. C.; BRITO E. A.; OLIVEIRA JÚNIOR S. Enriquecimento proteico de alimentos por levedura em fermentação semissólida: alternativa na alimentação animal. Revista Tecnol. e Ciên. Agropec., João Pessoa, v.3, n.3, p.47-53, set. 2009.

ARAÚJO L. F.; SILVA F. L. H.; BRITO E. A.; OLIVEIRA JÚNIOR S.; SANTOS E. S. Enriquecimento protéico da palma forrageira com Saccharomyces cerevisiae para alimentação de ruminantes. Arq. Bras. Med. Vet. Zootec., Belo Horizonte, v.60, n.2 Apr. 2008.

CAMPOS, A.R.N.; SANTANA, R.A.C.; DANTAS, J.P.; OLIVEIRA, L.S.C.; SILVA, F.L.H. Enriquecimento proteico do bagaço do pedúnculo de caju por cultivo semissólido. Revista de Biologia e Ciência da Terra, Belo Horizonte, v. 5, n. 2, p. 72-82, 2005.

CORREIA, R.; MAGALHÃES, M.; MACEDO, G. Protein enrichment of pineapple waste with Saccharomyces cerevisae by solid state processing. Journal of Scientific and Industrial Research, vol. 66, p. 259-262, 2007.

EMBRAPA - Empresa Brasileira de Pesquisa Agropecuária. Secagem e desidratação. Disponivel em: <http://www.agencia.cnptia.embrapa.br/gestor/tecnologia_de _alimentos/arvore/CONT000fid5sgie02wyiv80z4s473tokdiw 5.html>. Acesso em: 12 de março de 2015.

INSTITUTO ADOLFO LUTZ. NORMAS ANALÍTICAS DO INSTITUTO ADOLFO LUTZ. v. 1: Métodos químicos e físicos para análise de alimentos, 4. ed. São Paulo: IMESP, p. 97-122, 2008.

INSTITUTO BRASILEIRO DE GEOGRAFIA E ESTATÍSTICA - IBGE. Levantamento sistemático da produção agrícola. Rio de Janeiro/RJ. Vol. 29, n. 12, p. 1-88, dezembro, 2015.

KOBORI, C. N.; JORGE, N. Caracterização dos óleos de algumas sementes de frutas como aproveitamento de resíduos industriais. Revista Ciência e Agrotecnologia Lavras, v. 29, n. 5, p. 1008-1014, 2005.

LAUFENBERG, G.; KUNZ, B.; NYSTROEM, M. Transformation of vegetable waste into value added products: (A) the upgrading concept; (B) practical implementations.. Bioresource. Technology, v. 87, n. 2, p. 167-198, 2003. 
LEMOS, D. M.; OLIVEIRA, E. N. A.; SANTOS, D. C.; SOUSA E. P.; MATIAS, M. L. Composição físico-química de resíduos de abacaxi in natura e desidratado. Tecnologia \& Ciência Agropecuária, João Pessoa, v.4, n.2, p.53-56, 2010.

LUCIANO, R. C.; SERRALHEIRO, C.; ARAÚJO, L. F.; REIS, A. M.; AGUIAR, E. M.; BORBA, L. H. F. Enriquecimento proteico de resíduos do abacaxi para alimentação alternativa de ruminantes. Tecnologia \& Ciência Agropecuária, João Pessoa, v.8, n.4, p.47-52, 2014.

MATIAS, M. F. O.; OLIVEIRA, E. L.; MARGALHÃES, M. M. A., GERTRUDES, E. Use of fibres obtained from the cashew (Anacardium ocidentale, L) and guava (Psidium guayava) fruits for enrichment of food products. Brazilian Archives of Biology and Technology, v. 48, n. Especial, p. 143-150, 2005.

MARTINAZZO, A. P.; et. al. Modelagem matemática e parâmetros qualitativos da secagem de folhas de capim-limão (Cymbopogon citratus (DC.) Stapf. Revista Brasileira de Plantas Medicinais, v.12. n.4, 2010.

OCDE e FAO. Perspectivas Agrícolas no Brasil: desafios da agricultura brasileira 2015-2024. 2015. Disponível em:< https://www.fao.org.br/download/PA20142015CB.pdf> Acesso em: 06 de abril de 2015.

OLIVEIRA, M.M. (2007). Enriquecimento nutricional por bioconversão de resíduos agroindustriais para utilização na alimentação animal. 2007. 185p. Tese (Doutorado em Engenharia de Processos) - Universidade Federal de Campina Grande. Campina Grande, Paraíba. 2007.

OLIVEIRA M. M.; CAMPOS A. R. N.; SANTOS J. F.; OLIVEIRA M. E.; GOUVEIA J. P. G.; SILVA F. L. H.; Estudo do equilíbrio higroscópico da casca de abacaxi. Revista de Tecnologia e Ciências Agropecuária, João Pessoa, v.3, n.3, p.63-66, 2009.

OLIVEIRA, M. M.; CAMPOS, A. R. N.; SILVA, F. L. H. Enriquecimento nutricional dos resíduos do abacaxi (Ananás comosus L. Mer). Revista UNIVAP - Universidade do Vale do Paraíba. São José dos Campos, São Paulo, v. 13, n. 24. 2006.

OLIVEIRA, A. S. B. Estudo da secagem de casca de abacaxi visando desenvolvimento de chá a partir do produto seco. Campos dos Goytacazes: UENF, 2014. 82p. Dissertação Mestrado.
PELIZER, L. H.; PONTIRRI, M. H., MORAES, I. O. Utilização de resíduos agroindustriais em processos biotecnológicos como perspectiva de redução do impacto ambiental. Journal of Technology Management e Innovation, v. 2, n. 1, p. 118-127, 2007.

PIEDADE, J.; CANNIATTI - BRAZACA, S. G. Comparação entre o efeito do resíduo do abacaxizeiro (caules e folhas) e da pectina cítrica de alta metoxilação no nível de colesterol sanguíneo em ratos. Ciência e Tecnologia de Alimentos, v.23, n.2, p. 149-156, 2003.

PINTO, G. A. S.; BRITO, E. S.; ANDRADE, A. M. R.; FRAGA, S. L. P.; TEIXEIRA, R. B. Fermentação em estado sólido: uma alternativa para o aproveitamento e valorização de resíduos agroindustriais tropicais. Embrapa Agroindústria Tropical, $1^{\text {a }}$ edição, agosto 2005.

ROCHA, A.P.T. Estudo do desempenho de um leito de jorro convencional para secagem de leveduras. 2002. Dissertação (Mestrado em Engenharia de Processos Químicos) Universidade Federal de Campina Grande. Campina Grande, PB, 2002.

RODRIGUES, A. M. Efeito do cloreto de sódio na produção de proteínas (Shaccharamyces ceravisiae) em fermentação semi-sólida. Ciência e tecnologia, campinas, v.21, n.1, p.5762, 2001.

SENA, R. F.; NUNES, M.L. Utilização de resíduos agroindustriais no processamento de rações para carcinicultura. Revista Brasileira de Saúde e Produção Animal, Bahia, v.7, n.2, p.94-102, 2006.

SOUSA, B. A. A. Funcionalidades dos extratos fenólicos obtidos pelo cultivo semi-sólido de resíduos de abacaxi (Ananascomosus L.) e goiaba (Psidiumguajava L.). Natal: UFRN, 2009. 32p. Dissertação de Mestrado.

Souza, R. L. A.; Oliveira, L. S. C.; Silva, F. L. H.; Amorim, B. C. Caracterização da poligalacturonase produzida por fermentação semi-sólida utilizando-se resíduo de maracujá como substrato. Revista Brasileira de Engenharia Agrícola e Ambiental. v. 14, n. 9, p. 987-992, 2010.

UCHOA, A. M. A; COSTA, J. M. C.; MAIA, G. A.; SILVA, E. M. C.; CARVAlHO, A. F. F. U.; MEIRA, T. R. Parâmetros físico-químicos, teor de fibra bruta e alimentar de pós alimentícios obtidos de resíduos de frutas tropicais. Segurança Alimentar e Nutricional, Campinas, v. 15, n.2, p.58-65, 2008. 